\title{
PERSEPSI MASYARAKAT TERHADAP FUNGSI RAWA DI DAERAH MUSI RAWAS
}

\author{
Septi Kurnia ${ }^{1)}$, Meli Astriani2 ${ }^{*}$, Saleh Hidayat ${ }^{3)}$, \\ ${ }^{1,2,3)}$ Pendidikan Biologi, Program Pascasarjana, Universitas Muhammadiyah Palembang \\ *email: meliastriani.g201@gmail.com
}

Diterima 2 Februari 2021 disetujui 13 April 2021 diterbitkan 15 Mei 2021

\begin{abstract}
Swamps are part of relatively flat land along the coast, streams or lakes and there is vegetation in the form of water plants, leading to the land up to $\pm 100 \mathrm{~km}$ which is generally affected by tides from the surrounding rivers. The method used in this study is a qualitative descriptive method, namely a method of analysis that seeks to explain the conditions of the object of study according to certain criteria so that it can provide a real picture of what is happening in the research place. Public Perception of Swamp Function in the Musi Rawas Area. People living in O. mangunharjo Village use swamps to help farmers in the use of conversion of agricultural land. However, to find out people's perceptions of the function of swamps, there are ten questions to analyze the community's perceptions of the function of swamps in the Musi Rawas area. From the research activities, it is known that from the community's perception of the function of swampland in O. Mangunharjo village, Musi Rawas Regency, there are many activities or activities that occur around swamps carried out by farmers such as; looking for grass for livestock, then hoeing or plowing the fields and farmers who plant vegetables considering that swamps are very important to the balance of the environment, especially in the economy of the people around O. Mangunharjo village in Musi Rawas Regency, there are 2 respondents who do not know the impact of the damage the swamp ecosystem affects the surrounding environment and 3 respondents know its impact. Based on the results of the study, it can be concluded that the community knows the function of swamps in the surrounding settlements, namely that the presence of swamps can balance the ecological functions of the environment.
\end{abstract}

Keywords: Ecosystem, Perception, Society, Swamp, Musi Rawa

\section{PENDAHULUAN}

Persepsi merupakan proses aktif memilah, menata dan menafsirkan orang, obyek, kejadian, situasi dan aktivitas. Manusia memilah hanya hal ihwal tertentu dalam hidup mereka, lalu menata dan menafsirkannya secara selektif. Persepsi membentuk bagaimana manusia memahami orang lain dan dunianya sekaligus berbagai pilihan yang diambil dalam hidup mereka. Contohnya, bila seseorang beranggapan (perceive) orang lain sebagai bermusuhan atau menentangnya, maka ia bisa berinteraksi secara defensif atau meminimalkan komunikasi. Dengan sendirinya, persepsi memotivasi seseorang untuk bersikap dan bertindak dalam sebagian besar aktivitas hidupnya (Jayanti \& Arista, 2018).

Arifin dkk, (2017), mengemukakan bahwa persepsi merupakan kemampuan panca indera dalam menerjemahkan stimulus atau proses untuk menerjemahkan stimulus yang masuk ke dalam alat indera manusia. Persepsi manusia terdapat perbedaan sudut pandang dalam penginderaan yang mempersepsikan sesuatu itu baik atau persepsi yang positif maupun persepsi negatif yang akan mempengaruhi tindakan manusia yang tampak atau nyata.

Rawa merupakan bagian dari daratan yang relatif datar berada di sepanjang pantai, aliran sungai atau danau dan terdapat vegetasi berupa tumbuhan air, 
Florea : Jurnal Biologi dan Pembelajarannya, 8(1), 2021, 22-28

This is an open access article under the CC-BY-SA license (https://creativecommons.org/licenses/by-sa/4.o/) ISSN 2355-6102(print), ISSN 2502-0404(online)

DOI : 10.25273/florea.v8i1.8877

mengarah ke daratan sampai $\pm 100 \mathrm{~km}$ dimana umumnya mendapat pengaruh pasang surut air laut dari sungai sekitarnya. Pada musim hujan lahan rawa tergenang tetapi pada musim kemarau menjadi kering, bahkan pada beberapa lokasi lahan sebagian air tanah turun mencapai lebih dari zona perakaran tanaman (Pakpahan dkk, 2014).

Rawa merupakan dataran rendah yang selalu tergenang air, baik yang bersifat sementara maupun sepanjang waktu. Genangan ini disebabkan oleh suatu kondisi pembuangan air atau drainase yang buruk. Rawa bisa juga merupakan suatu cekunganyang menampung luapan air dari sekitarnya, misalnya luapan dari sungai akibat pengaruh terjadinya air pasang (Effendy, 2011). Sedangkan menurut Herawati (2015), rawa merupakan sebutan untuk semua daerah yang tergenang air, yang penggenangannya dapat bersifat musiman ataupun permanen dan ditumbuhi oleh tumbuhan (vegetasi).

Menurut Mustofa (2017), lahan rawa dapat dibagi menjadi beberapa kategori yaitu:

a. Berdasarkan istilah, lahan rawa dapat dibedakan menjadi dua bagian yaitu: (1) Rawa pasang surut (tidal swamps), yaitu rawa yang secara langsung terpengaruh oleh ayunan pasang surutnya air laut. (2) Rawa lebak (swampy atau nontidal swamps) adalah rawa yang mengalami genangan selama lebih dari tiga bulan dengan tinggi genangan terendah antar 25-50 $\mathrm{cm}$.

b. Berdasarkan letaknya, rawa bisa dibedakan menjadi 3 macam, yakni: (1) Rawa Dataran Rendah, yaitu rawa dataran rendah terjadi di daerah depresi yang membentuk permukaan datar dan cekung. (2) Rawa Dataran Tinggi yaitu rawa jenis ini terletak di daerah tinggi (daripada daerah disekitarnya) dan memiliki permukaan cekung. Sumber air rawa jenis ini berasal dari air hujan dan airnya tidak begitu asam. (3) Rawa
Peralihan, yaitu rawa jenis ini sebagian tanahnya bisa digunakan sebagai lahan pertanian

c. Berdasarkan tipologi, rawa dan kendala pengembangan dapat dibedakan menjadi lima yaitu:

1) Lahan potensial adalah lahan rawa yang meiliki jenis tanah sulfat masam dengan kadar pirit rendah atau $<2 \%$ pada jeluk $>50 \mathrm{~cm}$ dari permukaan tanah. Kendala produksi tergolong kecil karena mutu tanah tidak termasuk tanah tidak bermasalah.

2) Lahan sulfat masam adalah lahan rawa yang mempunyai lapisan pirit jeluk sedang atau $<50 \mathrm{~cm}$ yang juga disebut tanah sulfat masam potensial dan semua jenis tanah sulfat masam aktual. Kendalaproduksi dlam lahan jenis ini tergolong sedang sampai sangat berat.

3) Lahan gambut adalah bahan yang terbentuk dari bahan organik berupa bahan jenuh air dalam waktu lama atau telah diatus dengan kadar bahan organik paling sedikit $12 \%$, tanpa kandungan lempung atau paling tidak $18 \%$ apabila mengandung lempung paling tinggi $60 \%$ dan bahan tidak jenuh air selama kurang dari beberapa hari dengan kadar bahan organik paling sedikit $20 \%$. Kendala produksi pada jenis ini tergolong sedang sampai sangat berat.

4) Lahan salin atau lahan pantai adalah lahan rawa yang terkena pengaruh penyusupan air laut atau bersifat payau yang dapat termasuk lahan potesia, sulfat masam atau lahan gambut. Kendala produksi pada jenis lahan ini sedang sampai sangat berat terutama dalam hal tingkat kegaraman (salinitas).

5) Lahan lebak adalah rawa nonpasang surut adalah lahan rawa yang menalami genangan minimal $25-50 \mathrm{~cm}$ dengan lama genangan paling sedikit tiga bulan dalam setahun. Lahan lebak berdasarkan tinggi dapat dibagi menjadi empat tipologi yaitu lebak 
Florea : Jurnal Biologi dan Pembelajarannya, 8(1), 2021, 22-28

This is an open access article under the CC-BY-SA license (https://creativecommons.org/licenses/by-sa/4.o/)

ISSN 2355-6102(print), ISSN 2502-0404(online)

DOI : 10.25273/florea.v8i1.8877

dangkal (pematang), lebak tengahan, lebak dalam dan lebak sangat dalam (lebung). Kendala produksi sedang sampai sangat berat terutama dalam pengendalian air saat musim hujan.

Saat ini lahan optimal yang dapat digunakan untuk lahan pertanian semakin sempit. Alternatif yang dapat digunakan untuk sebagai lahan pertanian yaitu dengan memanfaatkan lahan suboptimal seperti lahan basah atau rawa lahan kering iklim kering, dan lahan kering masam.

Menurut Ar-Riza dan Alkasuma (2008), lahan rawa merupakan kekayaan alam yang dapat dimanfaatkan secara bijak agar dapat menjadi sumber pertumbuhan yang mampu mendorong laju pembangunan perekonomian dan memakmurkan rakyatnya. Oleh karena itu walaupun dalam era otonomi yang memberikan wewenang luas, pengelolaan lahan rawa pasang surut harus tetap mengindahkan kondisi dan sifat-sifat lahan yang khas dan unik.

Lahan rawa yang tersebar di beberapa wilayah Indonesia seperti Sumatera, Kalimantan, dan Papua di masa kini dan masa mendatang akan menjadi salah satu tumpuan sentra produksi pangan. Luas lahan rawa di Indonesia diperkirakan sekitar 33,4 juta ha, terdiri dari 13,29 juta ha lahan rawa lebakdan 20,1 juta ha lahan rawa pasang surut. Dengan pengelolaan dan penerapan teknologi yang tepat dan sesuai maka lahan rawa pasang surut sangat prospektif untuk dijadikan lahan pertanian (Widyantoro dkk, 2019).

Masyarakat yang tinggal di sekitar ekologi lahan basah mempunyai ketergantungan yang sangat besar terhadap ekosistem setempat. Karena itulah keberadaan mereka dapat berperan ganda: sebagai penjaga sekaligus perusak dari ekosistem tersebut. Untuk itu perlu dibangun suatu pola pengelolaan ekosistem yang melibatkan semua pihak, sehingga masyarakat dapat merasakan manfaatnya secara nyata, dan seterusnya keberadaan mereka diharapkan dapat menjaga ekosistem tersebut. Tujuannya adalah agar masyarakat ikut memiliki kepentingan untuk menggunakan segala sumber daya yang tersedia secara bertanggung jawab dan berkesinambungan (Zulkarnaini \& Lubis, 2018).

Menurut Panggabean dan Wiryawan (2016), menyatakan alasan masyarakat mengalih fungsikan lahannya disebabkan beberapa faktor, misalnya tidak optimalnya fungsi jaringan irigasi rawa dalam mensuplai dan mengeringkan lahan sawah. Ketidak cukupan air juga menyebabkan masyarakat mengganti penggunaanlahan sawah menjadi perkebunan karet dan kelapa sawit. Selain itu pilihan ekonomi dimana nilai jual karet setelah dikurangi biaya produksi dinilai masih lebih menguntungkan dibanding apabila menanam tanaman pangan, misalnya padi.

\section{METODE}

Metode yang digunakan dalam penelitian ini adalah metode diskriptif kualitatif, yaitu metode analisis yang berusaha menjelaskan kondisi objek kajian menurut kriteria-kriteria tertentu sehingga bisa memberikan gambaran yang sesungguhnya terjadi di tempat penelitian tersebut. Penelitian ini dilaksanakan pada tanggal 20 Januari 2021 di Kelurahan O. Mangunharjo Kecamatan Purwodadi Kabupaten Musi Rawas. Populasi dalam penelitian ini adalah keseluruhan masyarakat sekitar yang memanfaatkan lahan rawa di Kelurahan O. Mangunharjo Kecamatan Purwodadi Kabupaten Musi Rawas. Teknik pengambilan sampel yang digunakan dalam penelitian ini adalah menggunakan metode purposive sampling dimana sampel diambil sebanyak 5 orang responden. Teknik pengumpulan data yaitu observasi, wawancara, penyebaran angket (kuesioner) dan dokumentasi.

\section{HASIL DAN PEMBAHASAN}

Kelurahan O.Mangunharjo merupakan salah satu Desayang terletak di kecamatan Purwodadi Kabupaten Musi Rawas. Mata pencaharian masyarakat Kelurahan 
Florea : Jurnal Biologi dan Pembelajarannya, 8(1), 2021, 22-28

This is an open access article under the CC-BY-SA license (https://creativecommons.org/licenses/by-sa/4.o/) ISSN 2355-6102(print), ISSN 2502-0404(online)

DOI : 10.25273/florea.v8i1.8877

Mangunharjo terdiri dari petani, buruh, peternak, pengusaha kecil dan menengah, pegawai dan lain-lain.

Persepsi Masyarakat terhadap Fungsi Rawa di Daerah Musi Rawas. Masyarakat yang berada di Kelurahan O. mangunharjo memanfaatkan rawa untuk membatu petani dalam pemanfaatan alih fungsi lahan pertanian. Namun untuk mengetahui persepsi masyarakat terhadap fungsi rawa maka terdapat sepuluh pertanyaan untuk menganalisis Persepsi Masyarakat terhadap Fungsi Rawa di Daerah Musi Rawas.

Tabel 3.1 Kriteria Penilaian Persepsi Masyarakat di kelurahan O. Mangunharjo Kec. Purwodadi Kab. Musi Rawas

\begin{tabular}{|c|c|c|c|}
\hline No & $\begin{array}{c}\text { Kriteria } \\
\text { Penilaian }\end{array}$ & $\begin{array}{c}\text { Jawaban } \\
\text { Responden }\end{array}$ & $\begin{array}{l}\text { Persen- } \\
\text { tase }\end{array}$ \\
\hline \multirow[t]{5}{*}{1.} & Masyarakat & Ya, 5 orang & $100 \%$ \\
\hline & yang & Tidak, - & - \\
\hline & mengetahui & & \\
\hline & fungsi dari & & \\
\hline & lahan rawa & & \\
\hline \multirow[t]{7}{*}{2.} & Masyarakat & Ya, 5 orang & $100 \%$ \\
\hline & yang & Tidak, - & - \\
\hline & mengetahui & & \\
\hline & fungsi rawa & & \\
\hline & sebagai & & \\
\hline & keseimbangan & & \\
\hline & lingkungan & & \\
\hline \multirow[t]{3}{*}{3.} & Lahan rawa & Ya, 2 orang & $40 \%$ \\
\hline & yang & Tidak, 3 & $60 \%$ \\
\hline & $\begin{array}{l}\text { untuk pertanian } \\
\text { berdampak } \\
\text { pada ekosistem }\end{array}$ & orang & \\
\hline \multirow[t]{4}{*}{4.} & Masyarakat & Ya, 5 orang & $100 \%$ \\
\hline & $\begin{array}{l}\text { yang } \\
\text { mengetahui }\end{array}$ & Tidak, - & - \\
\hline & manfaat rawa & & \\
\hline & lingkungan & & \\
\hline \multirow[t]{3}{*}{5.} & Masyarakat & Ya, 4 orang & $80 \%$ \\
\hline & yang pernah & Tidak, 1 & $20 \%$ \\
\hline & $\begin{array}{l}\text { memanfaatkan } \\
\text { lahan rawa }\end{array}$ & orang & \\
\hline \multirow[t]{6}{*}{6.} & Masyarakat & Ya, 3 orang & $60 \%$ \\
\hline & yang & & \\
\hline & mengetahui & Tidak, 2 & $40 \%$ \\
\hline & $\begin{array}{l}\text { dampak dari } \\
\text { kerusakan }\end{array}$ & orang & \\
\hline & ekosistem rawa & & \\
\hline & $\begin{array}{l}\text { berpengaruh } \\
\text { terhadap }\end{array}$ & & \\
\hline
\end{tabular}

lingkungan

sekitar

7. Masyarakat yang memiliki

sikap peduli

terhadap

lingkungan

rawa (seperti

menjaga

kelestarian

lahan)

8. Masyarakat

yang melarang

seseorang yang

suka

Ya, 5 orang $\quad 100 \%$

Tidak, -

membuang orang

sampah

sembarangan di

daerah sekitar

rawa

9. Masyarakat

yang sering

menjaga

lingkungan

rawa dengan

membersihkan

lahan rawa dan

tidak

membuang

sampah

sembarangan

10. Masyarakat

yang memiliki

kesadaran dan

tanggung jawab

terhadap

pelestarian

lingkungan

disekitar rawa

Ya, 5 orang $\quad 100 \%$

Tidak, -

Ya, 4 orang $\quad 80 \%$

Tidak, $1 \quad 20 \%$

orang

Berdasarkan hasil wawancara dengan responden diketahui bahwa masyarakat di Desa O. Mangun Harjo Kecamatan Purwodadi Kabupaten Musi Rawas mempunyai tingkat pengetahuan yang tinggi terhadap fungsi rawa. Hal ini dapat dilihat dari pertanyaan yang diajukan kepada responden bahwa; 1) responden mengetahui lahan basah dan macammacam lahan basah, 2) responden mengetahui pentingnya lahan basah, 3) responden mengetahui fungsi dari lahan basah bagi keseimbangan lingkungan, 4) responden mengetahui fungsi lahan basah yang ada di pemukiman sekitar, 5) dengan 
Florea : Jurnal Biologi dan Pembelajarannya, 8(1), 2021, 22-28

This is an open access article under the CC-BY-SA license (https://creativecommons.org/licenses/by-sa/4.o/)

ISSN 2355-6102(print), ISSN 2502-0404(online)

DOI : 10.25273/florea.v8i1.8877

adanya lahan rawa dapat menyeimbangkan fungsi ekologi lingkungan, 6) lahan rawa yang dialihfungsikan sebagai lahan pertanian, 7) responden memanfaatkan lahan rawa sebagai pertanian menyebabkan dampak pada lingkungan, 8) kondisi rawa saat ini dibandingkan kondisi sebelumnya, 9) responden mengetahui faktor yang menyebabkan kerusakan lahan rawa, 10) kepedulian responden terhadap lahn rawa dan 11) responden mengajak masyarakat untuk menjagadan melestarikan lahan rawa.

Kriteria penilaian persepsi masyarakat terhadap fungsi rawa di Kelurahan $\mathrm{O}$. Mangunharjo terhadap fungsi rawa berdasarkan dari hasil wawancara bahwa; 1) lahan basah adalah wilayah-wilayah dimana tanahnya selalu berair kemudian macam-macam lahan basah yaitu rawa dan gambut, 2) pentingnya lahan basah karena lahan basah dapat dijadikan sebagai penunjang perekonomian masyarakat, 3) pentingnya lahan basah bagi keseimbangan lingkungan agar ekosistem berjalan dengan baik, 4) fungsi lahan basah yang ada di pemukiman bisa dijadikan kolam, 5) lahan rawa dapat menyeimbangkan fungsi ekologi lingkungan dengan cara membuat irigasi untuk persawahan, 6) lahan rawa yang dialihfungsikan sebagai lahan pertanian dapat menjadikan lingkungan jadi lebih bersih dan asri, 7) pemanfaatan lahan rawa sebagai lahan pertanian tidak menyebabkan dampak pada lingkungan, 8) kondisi rawa saat ini dibandingkan kondisi sebelumnya yaitu sekarang rawa sudah banyak dijadikan sebagai lahan persawahan, 9) faktor yang menyebabkan kerusakan lahan rawa yaitu jika dibiarkan akan ditumbuhi tanaman liar sehingga tidak terawat, 10) masyarakat selalu menjaga dan merawat lingkungan sekitar lahan rawa agar bersih dan tidak adanya hama yang mengganggu wilayah pertanian, 11) keikut sertaan masyarakat untuk menjaga dan melestarikan lahan rawa agar tidak merugikan petani.

Pengetahuan masyarakat terhadap fungsi dan pentingnya rawa sudah cukup baik namun masyarakat belum mengetahui dampak kerusakan ekosistem rawa yang disebabkan karena pembukaan lahan sebagai lahan pertanian. Lahan rawa yang dialihfungsikan sebagai lahan lahan pertanian dapat membantu perekonomian masyarakat sekitar karena lahan tersebut dapat ditanamani beberapa tanamaan seperti padi dan sayuran. Kemudian untuk kepedulian masyarakat sudah cukup baik dengan menjaga dan melestarikan lahan rawa sekitar dengan cara membersihkan sampah dan merawat lahan rawa dari tumbuhan liar yang mengganggu ekosistem lahan rawa tersebut. Sejalan dengan hal itu Haryono dkk (2012), menyatakan bahwa persepsi petani tentang lahan rawa bergantung pada pengalaman dan lingkungannya,sehingga pendapat mereka dapat berbeda antara di satu tempat dengan tempat lainnya. Masyarakat memiliki keahlian agraris rawa dalam membuka lahan dan menanaminya secara lebih luas untuk bahan pangan sehari-hari seperti padi, sagu, ubi, jagung dan lain sebagainya.

Selanjutnya dari hasil kuesioner yang telah dijawab oleh responden diketahui bahwa pada kriteria penilaian P1) 5 responden mengetahui fungsi dari lahan rawa. P2) 5 responden yang mengetahui fungsi rawa sebagai keseimbangan lingkungan. P3) 2 responden yang mengetahui bahwa lahan rawa yang difungsikan untuk pertanian berdampak pada ekosistem sedangkan 3 responden menjawab tidak tahu. P4) 5 responden yang mengetahui manfaat rawa terhadap lingkungan. P5) 4 responden yang pernah memanfaatkan lahan rawa dan 1 responden tidak pernah. P6) 3 responden yang mengetahui dampak dari kerusakan ekosistem rawa berpengaruh terhadap lingkungan sekitar sedangnkan 2 responden tidak tahu. P7) 5 responden yang memiliki sikap peduli terhadap lingkungan rawa. P8) 4 responden yang peduli seperti melarang seseorang yang suka membuang sampah sembarangan di daerah sekitar rawa sedangkan 1 responden tidak pernah 
Florea : Jurnal Biologi dan Pembelajarannya, 8(1), 2021, 22-28

This is an open access article under the CC-BY-SA license (https://creativecommons.org/licenses/by-sa/4.o/)

ISSN 2355-6102(print), ISSN 2502-0404(online)

DOI : 10.25273/florea.v8i1.8877

melarang orang yang membuang sampah sembarangan. P9) 5 responden sering menjaga lingkungan rawa dengan membersihkan lahan rawa dan tidak membuang sampah sembarangan. P10) 4 responden yang memiliki kesadaran dan tanggung jawab terhadap pelestarian lingkungan rawa dan 1 responden menjawab tidak.

Dari kegiatan penelitian diketahui bahwa dari persepsi masyarakat terhadap fungsi lahan rawa dikelurahan $\mathrm{O}$. Mangunharjo Kabupaten Musi Rawas adalah banyak kegiatan atau aktivitas yang terjadi di sekitar lahan rawa yang dilakukan oleh petani seperti; mencari rumput untuk ternak, kemudian mencangkul atau membajak sawah dan petani yang menanam sayuran mengingat lahan rawa sangat penting terhadap keseimbangan lingkungan terutama dalam perekonomian masyarakat yang ada di sekitar di kelurahan O. Mangunharjo yang ada di Kabupaten Musi Rawas.

\section{SIMPULAN}

Berdasarkan hasil penelitian dapat disimpulkan bahwa:

1. Masyarakat mengetahui fungsi rawa yang ada di pemukiman sekitar yaitu dengan adanya lahan rawa dapat menyeimbangkan fungsi ekologi lingkungan.

2. Lahan rawa yang dialihfungsikan sebagai lahan lahan pertanian dapat membantu perekonomian masyarakat sekitar karena lahan tersebut dapat ditanamani beberapa tanamaan seperti padi dan sayuran.

3. Dampak alihfungsi lahan rawa terhadap ekosistem yaitu sudah banyak lahan rawa yang dialihfungsikan menjadi lahan pertanian sehingga membuat keseimbangan ekosistem lahan rawa terganggu.

\section{DAFTAR PUSTAKA}

Arifin, H. S., Fuady, I., \& Kuswarno, E. (2017). Analisis Faktor yang
Mempengaruhi Persepsi Mahasiswa Untirta terhadap Keberadaan Perda Syariah di Kota Serang. Jurnal Penelitian Komunikasi dan Opini Publik, Vol 21 No (1) Hlm 88-101.

Ar-Riza, I., \& Alkasuma. (2008). Pertanian

Lahan Rawa Pasang Surut dan Strategi Pengembangannya dalam Era Otonomi Daerah. Jurnal Sumberdaya Lahan, Vol 2 No (2) Hlm 95-104.

Effendy. (2011). Drainase untuk Meningkatkan Kesuburan Lahan Rawa. Pilar Jurnal Teknik Sipil, Vol 6 No (2) Hlm 39-44.

Haryono, dkk. (2012). Lahan Rawa Penelitian dan Pengembangan. Jakarta: IAARD Press.

Herawati, N. (2015). Pengaruh Penambahan Tawas dan Kapur terhadap Kecepatan Pengendapan Air Rawa. Berkala Teknik, Vol 5 No (2) Hlm 884-889.

Jayanti, F., \& Arista, N. T. (2018). Persepsi Mahasiswa terhadap Pelayanan Perpustakaan Universitas Trunojoyo Madura. Kompetensi, Vol 12 No (2) Hlm 205-223.

Mustofa, R. (2017). Analisis Usahatani Kelapa Sawit Pola Swadaya pada Lahan Basah di Kabupaten Indragiri Hilir. Menara Ilmu, Vol 11 No (78) Hlm 128-138.

Pakpahan, D., Suripin, \& Sachro, S. S. (2014). Kajian Optimalisasi Sistem Irigasi Rawa (Studi Kasus Daerah Rawa Semangga Kabupaten Merauke Propinsi Papua). Jurnal MKTS, Vol 20 No (2) Hlm 155-166. Panggabean, E. W., \& Wiryawan, B. A. (2016). Strategi Pengembangan Lahan Irigasi Rawa di Daerah Rawa Pasang Surut Belawang-Kalimantan Selatan. Jurnal Irigasi, Vol 11 No (1) Hlm 1-10.

Widyantoro, Agustiani, N., \& Ruskandar, A. (2019). Peningkatan Pendapatan Petani Padi Rawa Pasang Surut Melalui Penerapan Teknologi Raisa 
Florea : Jurnal Biologi dan Pembelajarannya, 8(1), 2021, 22-28

This is an open access article under the CC-BY-SA license (https://creativecommons.org/licenses/by-sa/4.o/)

ISSN 2355-6102(print), ISSN 2502-0404(online)

DOI : 10.25273/florea.v8i1.8877

di Sumatera Selatan. Jurnal Agroswagati, Vol 7 No (2) Hlm 122-127.

Zulkarnaini, \& Lubis, E. E. (2018).

Pemberdayaan Masyarakat dalam
Pemanfaatan Ekosistem Rawa Gambut Secara Berkelanjutan. Jurnal Kebijakan Publik, Vol 9 No (2) Hlm 61-124. 